\title{
PENGARUH PEMBERIAN KOMPENSASI TERHADAP PRODUKTIVITAS KERJA PEGAWAI PADA KANTOR KECAMATAN TANJUNGPINANG KOTA
}

\section{THE EFFECT OF GIVING COMPENSATION TO THE EMPLOYEE PRODUCTIVITY OF TANJUNGPINANG KOTA SUB-DISTRICT}

\author{
Rita Asneli ${ }^{1}$, Dwi Septi Haryani ${ }^{2}$, Satriadi $^{3}$ \\ ${ }^{1}$ (Dinas Pendidikan Kota Tanjungpinang) \\ ${ }^{2}$ (Manajemen, STIE Pembangunan Tanjungpinang) \\ ${ }^{3}$ (Manajemen, STIE Pembangunan Tanjungpinang) \\ ${ }^{1}$ sdnegeri014tpitimur@yahoo.com, ${ }^{2}$ dwiseptih@gmail.com, ${ }^{3}$ satriadi456@gmail.com
}

\begin{abstract}
Abstrak
Kompensasi merupakan hal yang sangat penting adanya di suatu organisasi, baik itu swasta ataupun pemerintahan.maka dari itu pemberian kompensasi hendaknya mengikuti peraturan yang telah diberikan dan sesuai dengan kesepakatan serta asas yang sesuai, dimana tidak ada kerugian diantara organisasi maupun pegawai itu sendiri. kompensasi dapat meningkatkan produktivitas pegawai disuatu organisasi dimana hal ini ditunjukkan oleh beberapa faktor yang ada. pada penelitian ini kami mengangkat judul "analisis pengaruh pemberian kompensasi terhadap produktivitas kerja pegawai pada Kantor Kecamatan Tanjungpinang Kota" yang terletak di kp.bugis, Tanjungpinang. dimana kami mendapatkan hasil bahwa terdapat pengaruh signifikan yang terjadi antara Variabel Kompensasi (X) terhadap Variabel Produktivitas Kerja (Y) sebesar $22 \%$. walaupun hal tersebut terjadi dengan signifikan, tetapi menurut kami hal itu perlu ditingkatkan kembali.
\end{abstract}

Kata Kunci; Kompensasi, Produktivitas Kerja, Pegawai

\begin{abstract}
Compensation is a very important thing in an organization, whether private or government. therefore the compensation should follow the rules given and in accordance with the agreement and the appropriate principle, where there is no harm between the organization and the employees themselves. compensation can increase employee productivity in an organization where this is indicated by several factors. in this study we raised the title "analysis of the effect of compensation on employee productivity at the District Office Tanjungpinang City" located in kp.bugis, Tanjungpinang. where we get the result that there is significant influence that happened between Variable Compensation (X) to Variable Work Productivity (Y) equal to $22 \%$. although it does happen significantly, but we think it needs to be improved again.
\end{abstract}

Keywords; Compensation, Productivity, Employee

\section{PENDAHULUAN}

Kondisi ekonomi saat ini, perusahaan harus menyiapkan sumber daya mnausia (SDM) untuk mempertahankan posisi kompetitifnya. Hal ini memerlukan sistem dan manajmen yang baik guna mengintegrasikan proses-proses terhadap karyawan dan informasi denga proses bisnis dan usaha yang strategis untuk meraih hasil yang sangat optimal. Salah satu tugas penting dalam manajemen SDM adalah manajemen kompensasi. Hal ini merupakan tugas yang sangat rumit yang sering timbul pada tiap periode, menuntut keakuratan dan tidak dapat ditunda, dimana termasuk mengolah dan mengimplementasikan secara baik dan benar dari setiap scenario kompensasi yang harus disertakan dalam proses penggajian. 
Bukan hanya disektor swasta melainkan juga di sektor pemerintahan.Dimana kompensasi menjadi hal mutlak yang dapat dijadikan tolak ukur pegawai dalam peningkatan produktivitas karyawan tersebut.Seperti halnya pada objek penelitian kami di Kantor Camat TanjungPinang Kota yang berlokasi di Kampung Bugis, TanjungPinang.Dimana kami mengangkat persoalan kompensasi pada instansi pemerintahan tersebut.Penelitian ini dilakukan dengan tujuan untuk mengetahui pengaruh antara kompensasi terhadap produktivitas kerja pegawai di Kantor Camat Tanjungpinang Kota.

\section{Kompensasi}

Kompensasi menurut Hasibuan (2004) adalah semua pendapatan yang berbentuk uang, barang langsung atau tidak langsung, yang diterima karyawan sebagai imbalan atas jasa yang diberikan kepada perusahaan.Menurut Sikula dalam Hasibuan mengatakan kompensasi adalah segala sesuatu yang di konstitusikan atau dianggap sebagai suatu balas jasa atau ekuivalen.

Berdasarkan defenisi-defenisi diatas, secara ringkas dapat diambil kesimpulan, kompensasi adalah semua balas jasa berbentuk uang, barang langsung atau tidak langsung yang diberikan kepada para karyawan atas konstribusi karyawan dalam mencapai tujuan atau sasaran organisasi.

Pemberian kompensasi umumnya bertujuan untuk kepentingan perusahaan, karyawan, dan pemerintah/masyarakat.Supaya tujuan tercapai dan memberikan kepuasan bagi semua pihak hendaknya program kompensasi ditetapkan berdasarkan prinsip adil dan wajar, undang-undang perburuhan, serta memperhatika internal dan ekternal konsistensi.

Tujuan pemberian kompensasi anyata lain sebagai berikut:

a. Ikatan kerja sama

Dengan pemberian kompensasi terjalinkah ikatan kerja sama formal antara majikan dengan karyawan. Karyawan harus mengerjakan tugas-tugasnya dengan baik, sedangkan majikan wajib membayar kompensasi sesuai dengan perjanjian yang disepakati.

b. Kepuasan kerja

Dengan kompensasi, karyawan akan dapat memenuhi kebutuhan-kebutuhan fisik, sosial, dan egoistiknya sehingga memperoleh kepuasan kerja dari jabatanya.

c. Pengadaan efektif

Jika program kompensasi ditetapkan cukup besar, pengadaan karyawan yang qualified untuk perusahaan akan lebih mudah. 


\section{d. Motivasi}

Jika kompensasi diberikan cukup besar, manajer aka mudah memotivasi bawahanya.

e. Stabilitas karyawan

Dengan kompensasi atas prinsip adil dan layak serta eksternal konsistensi yang kompentatif maka stabilotas karyawan lebih tgerjamin karena turnover relative kecil.

f. Disiplin

Dengan pemberian kompensasi yang cukup besar maka disiplin karyawan semakin baik. Mereka akan menyadari dan menaati peraturan-peraturan yang ada.

g. Pengaruh serikat buruh

Dengan program kompensasi yang baik pengaruh serikat buruh dapat dihindarkan dan karyawan akan berkonsentrasi pada pekerjaannya.

h. Pengaruh pemerintah

Jika program kompensasi sesuai dnegan undang-undang perburuhan yang berlaku maka intervensi pemerintah dapat dihindarkan.

Metode kompensasi terdiri dari 2 metode, yaitu: metode tunggal, standar gajinya hanya satu yaitu ijazahterakhir dari pendidikan formal, sedangkan metode jamak dtandar gajinya banyak dan kurang jelas seperti yang sering terdapat pada perusahaan perusahaan swasta.Sistem dan kebijakan pemberian kompensasi hendaknya memberikan kepuasan bagi karyawan yang disusun dengan unsure yang terdiri dari kompensasi langsung dan tidak langsung, laba untuk perusahaan, serta barang/jasa yang berkuaitas dan harga yang pantas.Jadi, semua pihak mendapatkan kepuasan dari sistem pengupahan yang diterapkan.

Definisi kompensasi nonfinansial menurut Simamora kompensasi non finansial terdiri dari kepuasan yang diperoleh seseorang dari pekerjaan itu sendiri, atau dari lingkungan psikologis, dan atau fisik dimana orang itu bekerja. Kompensasi non finansial dibagi menjadi dua , yaitu:

a. Pekerjaan adalah segala aktifitas yang dilakukan oleh pegawai dalam rangka menyelesaikan tugas-tugas yang telah dibebankan padanya. Pegawai akan menerima kompensasi non keuangan berupa kepuasan kerja dengan melakukan pekerjaan yang dirasa tepat bagi pegawai, antara lain :

1) Tugas-tugas yang menarik

2) Tantangan bagi sebagian pegawai yang merasakan pekerjaan yang kurang menantang/ monoton akan dapat memacu ketidakpuasan pegawai atau bahkan membuat pegawai 
tersebut keluar dari organisasinya demi mencari pekerjaan yang dianggap lebih menantang.

3) Tanggung Jawab yaitu suatu bentuk kepercayaan yang diberikan oleh organisasi terhadap pegawainya untuk menyelesaikan pekerjaan.

4) Pengakuan yaitu suatu bentuk sikap yang diberikan organisasi kepada pegawai atas keberadaan dan kedudukannya ditengah-tengah organisasi sebagai salah satu anggota yang berkecimpung dalam organisasi.

5) Rasa Pencapaian yaitu perasaan pegawai atas pencapaian dalam keberhasilannya untuk menyelesaikan pekerjaan yang dibebankan padanya dengan baik.

b. Lingkungan pekerjaan adalah kondisi lingkungan dalam suatu organisasi dimana para pegawai melaksanakan tugas dan pekerjaannya sehari-hari. Adapun lingkungan pekerjaan terdiri atas :

1) Kebijakan-kebijakan yang sehat maksudnya adalah kebijakan-kebijakan yang dibuat oleh manajemen hendaknya harus adil tidak hanya mendukung organisasi saja sehingga organisasi terkesan sewenang- wenang dalam menentukan kebijakan bagi pegawai, selain itu kebijakan- kebijakan tersebut haruslah mampu mendukung pegawai dalam menyelesaikan pekerjaan serta juga berfungsi sebagai sarana untuk membela kepentingan pegawai dengan demikian kepuasan kerja akan diperoleh pegawai.

2) Supervisi yang kompeten maksudnya adalah pengawas yang bijaksana dan cakap serta mampu memberikan petunjuk-petunjuk, dukungan dan tanggung jawab yang nyata dalam proses penyelesaian pekerjaan yang rumit dan kompleks, selain itu pengawas juga memberikan kesempatan bagi pegawainya untuk ikut berpartisipasi dan dalam segala hal yang berkaitan dengan penyelesaian pekerjaannya sehingga secara otomatis kemampuan pegawai juga ikut berkembang sehingga tercipta kepuasan kerja bagi pegawai.

3) Teman kerja yang menyenangkan akan meningkatkan semangat kerja pegawai karena dengan keeratan hubungan dengan teman kerja yang menyenangkan akan membantu proses penyelesaian pekerjaan sehingga pekerjaan akan selesai dengan mudah dan cepat, selain itu dengan keeratan hubungan dengan rekan kerja mampu mengurangi ketegangan, kecemasan dalam kelompok, sehingga pegawai akan lebih mampu menyesuaikan diri dengan tekanan pengaruh pekerjaan. 
4) Lingkungan kerja yang nyaman maksudnya adalah tempat kerja seseorang pegawai yang terdiri dari lingkungan fisik dan lingkungan nonfisik yang dapat mempengaruhi pegawai dalam menyelesaikan tugas-tugasnya.

Menurut pendapat Handoko, bahwa kegiatan-kegiatan pengaturan lingkungan kerja juga mencakup pengendalian suara bising, pengaturan penerangan tempat kerja, pengaturan kelembaban dan suhu udara, pelayanan kebutuhan pegawai, pengaturan penggunaan warna, pemeliharaan kebersihan lingkungan, dan penyediaan berbagai fasilitas yang dibutuhkan pegawai, seperti kamar mandi, ruang ganti pakaian, dan sebagainya. Menurut Dessler, kompensasi non finansial atau ganjaran non finansial merupakan hal-hal yang tidak mudah dikuantifikasi, yaitu ganjaran-ganjaran seperti pekerjaan yang lebih menantang, jam kerja yang lebih luwes/ fleksibel, dan kantor yang lebih bergengsi.

\section{Produktivitas Kerja}

Menurut Siagian (2001) menyatakan bahwa produktivitas kerja adalah kemampuan memperoleh manfaat yang sebesa-besarnya dari sarana dan prasarana yang tersedia dengan menghasilkan tujuan yang optimal bahkan kalau bisa yang maksimal.Suyoto (2012) mengatakan bahwa produktivitas kerja adalah ukuran yang menunjukkan pertimbangan antara input dan output yang dikeluarkan prusahaan serta peran tenaga kerja yang dimiliki persatuan waktu.Berdasarkan pengertian tersebut maka dapat disimpulkan bahwa produktivitas kerja karyawan adalah keseluruyhan output yang dihasilkan oleh karyawan yang diukur berdasarkan ukuran waktu dengan memaksimalkan segala sumber daya yang ada

\section{METODOLOGI}

Jenis penelitianyang digunakan dalam penelitian ini yakni penelitian asosiatif dengan pendekatan kuantitatif dimana hasil penelitian ini akan berupa angka yang sistematik menggunakan system spss untuk melakukan statistika atau untuk melihat pengaruh dimana sesuai dengan judul karya tulis ini.Untuk tempat penelitian ini kami memilih kantor camat Tanjungpinang kota di kampung Bugis,.kami akan menyebarkan angket kepada 23 karyawan yang ada pada instansi pemerintahan tersebut. Untuk teknik pengambilan data kami menggunakan teknik penyebaran angket atau kuesioner.Dimana seperti yang kita ketahui angket atau kuesioner adalah teknik pengumpulan data dengan memberikan formulir yang berisikan pertanyaan-pertanyaan untuk mendapatkan informasi dari seseorang ataupun beberapa orang yang biasa disebut responden untuk mendapatkan jawaban atau tanggapan 
serta informasi yang dibutuhkan oleh peniliti.Kemudian data yang diperoleh dianalisis secara deskriptif.

\section{PEMBAHASAN}

\begin{tabular}{|c|c|c|c|c|c|c|}
\hline \multirow[b]{3}{*}{ Model } & & \multicolumn{4}{|c|}{ Coefficients $^{\mathrm{a}}$} & \\
\hline & & \multicolumn{2}{|c|}{ Unstandardized Coefficients } & \multirow{2}{*}{$\begin{array}{l}\text { Standardized } \\
\text { Coefficients } \\
\text { Beta }\end{array}$} & \multirow[b]{2}{*}{$t$} & \multirow[b]{2}{*}{ Sig. } \\
\hline & & B & Std. Error & & & \\
\hline 1 & (Constant) & 17,805 & 6,740 & & 2,642 & 015 \\
\hline & KOMPENSASI & ,472 & ,194 & ,469 & 2,433 & ,024 \\
\hline
\end{tabular}

a. Dependent Variable: PRODUKTIVITAS_KERJA

Pada Tabel 1 pada kolom B pada Constant (a) adalah 17,805, sedangkan nilai Kompensasi adalah 0,472, sehingga persamaan regresinya dapat ditulis sebagai berikut: $\mathrm{Y}=\mathbf{a}+\mathbf{b X}$ atau $17,805+0,472 X$

Koefisien b dinamakan koefisien arah regresi dan menyatakan perubahan rata-rata variabel $\mathrm{Y}$ untuk setiap perubaan variable $\mathrm{X}$ sebesar satu satuan. Perubahan ini merupakan pertambahan bila $b$ bertanda positif dan penurunan bila $b$ bertanda negative. Sehingga dai persamaan tersebut dapat diterjemahkan:

1. Konstanta sebesar 17,805 menyatakan bahwa jika tidak ada nilai kompensasi maka nilai produktivitas kerja sebesar 17,805 .

2. Koefisien regersi $X$ sebesar 0,472 menyatakan bahwa aetiap penambahan 1 nilai kompensasi, maka nilai produktivitas bertamabah 0,472 .

Hasil uji regresi diatas menggambarkan persamaan regresi ouput ini juga menampilkan uji signifikansi dengan uji t yaitu untuk mengetahui apakah ada pengaruh yang signifikan variabel X secara parsial terhadap variabel Y.

Hipotesis :

1. Ho : Ditolak.

2. H1 : Diterima adanya pengaruh signifikan antara variable Kompensasi terhadap variable Produktivitas dengan nilai t hitung sebesar 2,433 dengan nilai signifikansi $0,024<0,050$. 


\section{Tabel 2}

\section{Model Summary}

\begin{tabular}{lr|r|r|r}
\multicolumn{1}{l|}{$\begin{array}{l}\text { Model } \\
\text { R }\end{array}$} & \multicolumn{2}{|c|}{ R Square } & Adjusted R Square & Std. Error of the Estimate \\
\hline 1 &, $469^{a}$ &, 220 &, 183 & 4,52399 \\
\hline
\end{tabular}

a. Predictors: (Constant), KOMPENSASI

Tabel 2 menjelaskan mengenai besarnya nilai korelasi atau hubungan $(\mathrm{R})$ yaitu sebesar 0,469 dan dijelaskan besarnya presentase pengaruh variable bebas terhadap variable terikat yang disebut koefisien determinasi yang merupakan hasil dari penguadratan R. dari output tersebut diperoleh koefisien determinansi (R2) sebesar 0,220, yang mengandung pengertian bahwa pengaruh variable bebas (Kompensasi) terhadap variable terikat (Produktivitas kerja) adalah sebesar $22 \%$, sedangkan sisanya dipengaruhi oleh variable lain.

\section{KESIMPULAN}

Simpulan dari penelitian ini yakni variabel kompensasi $(\mathrm{X})$ memberikan pengaruh yang signifikan terhadap variabel produktivitas (Y) sebesar 22\%.Dengan tingkat signifikansi probabilitas $0,024<0,050$. Dengan demikian maka dapat disimpulkan pengaruh yang signifikan diberikan oleh variabel Kompensasi terhadap variable produktivitas kerja.Berdasarkan penelitian ini saran kami kepada kantor kecamatan Tanjungpinang kota guna meningkatkan persentase pengaruh diatas agar menjadi lebih baik, yaitu:

1. Hendaknya instansi tetap memperhatikan factor kompensasi financial, yaitu dengan mengevaluasi besarnya gaji bagi karyawan, menyesuaikan nilai dari gaji yang diberikan kepada pegawai dan menyesuaikan dengan peraturan pemerintah agar motivasi kerja yang dimiliki pegawai semakin menjadi dan tentunya akan mempengaruhi produktivitas di intansi tersebut.

2. Hendaknya instansi juga memberikan factor kompensasi non financial, yaitu pelatihan, mental fisik karyawan, dan hubunganantara atasan dan bawahan agar motivasi kerja yang dimiliki oleh pegawai semakin tingi dan tentunya akan meningkatkan produktivitas.

Hendaknya instansi juga harus memperhatikan peningkatan produktivitas kerja karyawan yaitu perbaikan terus menrus, peningkatan mutu hasil kerja, pemberdayaan SDM sehingga instansi akan mampu mewujudkan peningkatan produkvitas kerja pegawai 


\section{REFERENSI}

Abdussamad, Z. (2014). Pengaruh Kompensasi Terhadap Produktivitas Kerja Karyawanpada PT. Asuransi Jiwasraya Gorontalo. Jurnal Manajemen/Volume XVIII, No. 03, Oktober 2014: 456-466.

Alimuddin, W. (2012). Pengaruh Kompensasi Terhadap Produktivitas Karyawan Pada PT. Bakrie Telecom Area Makassar. jurnal FAKULTAS EKONOMI DAN BISNIS .

Dewi, V. F. (2014). Pengaruh Kompensasi Terhadap Produktivitas Kerja Pegawai Pada Kantor Dinas Perindustrian, Perdagangan, Koperasi Dan Umkm Samarinda. eJournal Ilmu Administrasi Bisnis, 2014, 2 (2): 230-244 ISSN 2355-5408, ejournal.adbisnis.fisipunmul.ac.id .

Djubaini, F. (2017). Influence Of Fingerprint And Compensation Use Of Employees 'Discipline On The Secretary Of The City Of Manado City. Jurnal EMBA .

Firmandari, N. (2014). Pengaruh Kompensasi Terhadap Kinerja Karyawan Dengan Motivasi Kerja Sebagai Variabel Moderasi. EKBISI, Vol. IX, No. 1, Desember 2014, hal. 25 - 34 ISSN:1907-9109.

Hasibuan, D. H. (2014). Manajemen Sumber Daya Manusia. jakarta, DKI Jakarta, Indonesia: PT. Bumi Aksara.

Lubis, A. A. (2005). pengaruh kompensasi terhadap Produktivitas Kerja Karyawan Pada PT. Rolimex Kimia Nusamas Medan. skripsi S1 manajemen USU .

Muljani, N. (2002). Kompensasi Sebagai Motivator Untuk Meningkatkan. Jurnal Manajemen \& Kewirausahaan Vol. 4, No. 2, September 2002: 108 - 122.

Ni Kadek Yuliandari, I. W. (2014). Pengaruh Kompensasi dan Lingkungan Kerja Terhadap Produktivitas Kerja Karyawan Bagian Loster Pada UD Yuri Desa Pangkung Buluh Kecamatan Melaya Kabupaten Jembrana. e-Journal Bisma Universitas Pendidikan Ganesha.

PB, T. (2010). Manajemen Sumber Daya Manusi Perspektif Partnership dan Kolektivitas. Jakarta: ORYZA.

Posuma, C. O. (2013). Kompetensi, Kompensasi, Dan Kepemimpinan Pengaruhnya Terhadap Kinerja Karyawan Pada Rumah Sakit Ratumbuysang Manado.Jurnal EMBA Vol.1 No.4 Desember 2013. 
Prabowo, Y. A. (2017). Pengaruh Motivasi, Disiplin Dan Kompensasi Kerja Terhadap Kinerja Karyawan Pada PT. Pos Indonesia Kantor Pos Wonogiri. Jurnal Manajemen Fakultas Ekonomi dan Bisnis .

Sari, E. L. (2015). Pengaruh Pemberian Kompensasi Terhadap Produktivitas Kerja Karyawan Pada PT. Ryan Jaya Persada. Jurnal Ilmu dan Riset Manajemen. 